\title{
BMJ Open Arrabidaea chica for oral mucositis in patients with head and neck cancer: a protocol of a randomised clinical trial
}

\author{
Núbia de Cassia Almeida Queiroz, ${ }^{1}$ Michelle Pedroza Jorge, ${ }^{1}$ \\ Ilza Maria de Oliveira Sousa, ${ }^{1}$ Carmen Silvia Passos Lima, ${ }^{2}$ \\ Maria Christina de Miranda Matias, ${ }^{2}$ Ana Cristina Dal Rio, ${ }^{2}$ \\ Eduardo Baldon Pereira, ${ }^{2}$ Victória Hahn Kakas Galassi, ${ }^{1}$ \\ João Ernesto de Carvalho, ${ }^{1}$ Tais Freire Galvao, ${ }^{1}$ Mary Ann Foglio ${ }^{1}$
}

To cite: Queiroz NdCA, Jorge MP, Sousa IMd0, et al. Arrabidaea chica for oral mucositis in patients with head and neck cancer: a protocol of a randomised clinical trial. BMJ Open 2018;8:e019505. doi:10.1136/ bmjopen-2017-019505

- Prepublication history and additional material for this paper are available online. To view these files, please visit the journal online (http://dx.doi. org/10.1136/bmjopen-2017019505).

Received 16 November 2017 Revised 8 June 2018 Accepted 29 August 2018

\section{Check for updates}

(c) Author(s) (or their employer(s)) 2018. Re-use permitted under CC BY-NC. No commercial re-use. See rights and permissions. Published by BMJ.

${ }^{1}$ Faculty of Pharmaceutical Sciences, State University of Campinas, Sao Paulo, Brazil

${ }^{2}$ Faculty of Medical Sciences, State University of Campinas, Sao Paulo, Brazil

Correspondence to Professor Tais Freire Galvao; taisgalva0@gmail.com

\section{ABSTRACT}

Introduction Oral mucositis is an iatrogenic condition of erythematous inflammatory changes which tends to occur on buccal and labial surfaces, the ventral surface of the tongue, the floor of the mouth and the soft palate of patients receiving chemotherapy. This protocol of ongoing randomised parallel group clinical trial aims to access the therapeutic effect of an herbal gel containing $2.5 \%$ Arrabidaea chica Verlot standardised extract on oral mucositis in patients with head and neck cancer compared with low-level laser therapy.

Methods and analysis Patients with head and neck cancer held at Clinics Hospital of University of Campinas, Sao Paulo, who develop early signs/symptoms of oral mucositis are eligible. Baseline characteristics of participants include oral mucositis grade and quality of life assessments. Enrolment started in November 2017 with allocation of patients to one of the study groups by means of randomisation. Patients will be treated either with Arrabidaea chica or laser until wound healing. Monitoring includes daily assessment of mucositis grade and diameter measurement by photographs and millimetre periodontal probe. Treatments will be concluded once mucositis is healed. A blinded assessor will evaluate mucositis cure after referred by the study team. At this point, the gel tube will be weighed to indirectly assess patient's compliance. At close-out, data will be analysed by a blinded researcher following the procedures described in the statistical analyses.

Ethics and dissemination This clinical trial was approved by the ethics committee of research in humans at the Faculty of Medical Sciences of University of Campinas (report no. 1,613,563/2016). Results from this trial will be communicated in peer-reviewed publications and scientific presentations.

Trial registration number $\mathrm{RBR}-5 \times 4397$.

\section{INTRODUCTION}

Oral mucositis is an iatrogenic condition of erythematous inflammatory changes, which tends to occur on buccal and labial surfaces, the ventral surface of the tongue, the floor of the mouth and the soft palate of
Strengths and limitations of this study

- This is a pragmatic randomised clinical trial that will assess the effects of an herbal preparation for the treatment for the treatment of oral mucositis in patients with head and neck cancer.

- The results may bring an alternative for patients who cannot afford or do not have access to laser therapy.

- The lack of blinding of patients and study personnel is the main weakness of the study; blinding of outcomes assessors and data analysts were planned to improve confidence in the data to be provided by the study.

patients receiving chemotherapy. ${ }^{1}$ Severity of oral mucositis ranges from superficial sore erythema to complete mucosal ulceration in the oral cavity, pharynx and oesophagus. Therefore, patient's life quality is affected since oral mucositis is associated with considerable pain and dysphagia which also complicates the nutritional intake, increases susceptibility to infections and leads to cancer treatment interruption. ${ }^{2}$ Oral mucositis is a frequent event in patients with head and neck cancer treated with radiotherapy and/or chemotherapy. ${ }^{3}$ This is one of the most potentially troublesome side effects of combination therapy which can affect patient's compliance to treatment, life quality and consequently impact on global oncological outcomes. Hence, timely and adequate management of mucositis is of paramount importance. ${ }^{34}$

Effective therapeutic drugs for healing oral mucositis are still lacking. ${ }^{5}$ Current approach focuses on the management of pain and encouragement of eating, especially in chemotherapy-induced mucositis. ${ }^{6}$ Cryotherapy, laser treatment and the construction of a radiation area to protect the oral tissues during irradiation as well as a range 
of mouthwash options are among treatment options for mucositis. ${ }^{7}$ Low-level laser therapy, which has a beneficial effect during the inflammation, proliferation and maturation phases of the wound healing process, is a safe adjunct treatment for oral mucositis. ${ }^{8}$ Despite such treatment options, there is still a need for other feasible and affordable therapies more accessible to the public. ${ }^{9}$

In Brazil, a list of plants of interest to the unique system of health, RENISUS, was launched..$^{10}$ Arrabidaea chica (Humb. \& Bonpl.) Verlot, rich in anthocyanins, was included in RENISUS as a result of previous reports on healing and antiulcerogenic activity in preclinical studies. ${ }^{1112}$ The crude standardised A. chica extract dried by atomisation favoured calcaneus tendons healing in animal model, ${ }^{13}$ as well as the reduction of cutaneous ulcerations, evaluated in experimental in vivo healing experimental model with semisolid basis incorporated extract. ${ }^{14}$ The extract of Arrabidaea chica decreased 96\% of the area of the wound in dermal ulcer models of male Wistar rats. ${ }^{12}$ In diabetic Wistar rats, A. chica extract diminished the ulcerated area by $85 \% .^{12}$

Preclinical toxicity study with $A$. chica chloroform fraction evaluated on Salmonella test and in vivo micronucleus test from mice bone marrow confirmed that the fraction did not present any mutagenic or genotoxic potential, inferring the extract to be genetically safe. ${ }^{15}$ In gastrointestinal tract mucositis and oral mucositis experimental models induced by 5-fluoracil in mice and hamsters showed an increase in animals' survival when treated with A. chica extract in comparison with the negative control, furthermore a decrease of diarrhoea and increase of food intake was observed. ${ }^{16}$ In phase 1 clinical trial, the gel containing $2.5 \%$ of $A$. chica extract showed to be safe without any adverse events (unpublished data).

This ongoing randomised parallel group clinical trial will access the therapeutic effect of A. chica Verlot standardised extract on oral mucositis in patients with head and neck cancer compared with low-level laser therapy. Present protocol reports the planned methods of a randomised, parallel, prospective and open-label clinical trial.

\section{METHODS}

\section{Trial registration}

This protocol was registered at Brazilian Registry of Clinical Trials (www.ensaiosclinicos.gov.br).

\section{Study setting}

The study is ongoing at the Oncology and Radiotherapy Departments of Clinic Hospital, University of Campinas (HC-Unicamp), Campinas, Sao Paulo, Brazil. This unit is specialised in chemotherapy and radiotherapy of solid cancers, and treats both outpatients and inpatients. Yearly, approximately 1200 patients are followed and 1000 new patients initiate treatment.

\section{Eligibility criteria}

Men and women over 18 years of age with squamous cell carcinoma of the head and neck under chemotherapy with cisplatin or carboplatin associated with radiotherapy that develop early signs/symptoms of oral mucositis are eligible. To guarantee oral mucositis diagnosis soundness, an experienced oncologist (CSPL) will identify eligible patients and refer them for enrolment.

Patients with a tumour of a histological type other than carcinoma, patients with nasopharyngeal tumour, with ulcerative lesions or infections in the oral cavity before treatment will be excluded.

Blood count for myelosuppression evaluation, serum urea and creatinine dosages for evaluation of renal function and alanine aminotransferase, aspartate aminotransferase and serum bilirubin, will be performed to assess liver function before and after treatment in accordance with the standard procedures for patients with head and neck cancer.

According to the institutional protocol, patients receive cisplatin $\left(80-100 \mathrm{mg} / \mathrm{m}^{2}\right)$ or carboplatin (area under the concentration-versus-time curve (AUC) AUC5, three doses each 21 days or AUC2, seven weekly doses) based on ideal physical condition (evaluated by the Karnofsky index) and evaluated with or without renal, neurological or cardiological comorbidities. The total radiation dose will be set at $75 \mathrm{~Gy}$ in 35 daily fractions (2 Gy/day except weekends), at HC-Unicamp, under the supervision of a radiotherapist (EBP). Patients receive pain and other symptomatic measures as needed, to either control the disease or treatment effects.

\section{Interventions}

Patients will be randomised to A. chica or low-level laser therapy.

A. chica are provided in tubes of $30 \mathrm{~g}$ of a $2.5 \%$ of the active standardised extract in gel formulation, as depicted in table 1. Individuals enrolled in A. chica arm will receive tubes of the herbal gel and will be instructed to apply the product three times daily with sufficient volume to cover up the extent of the lesion after sanitising the oral cavity. The first application is made under researcher supervision, after enrolment. Furthermore, such patients will be instructed not to ingest water and food for a period of $20 \mathrm{~min}$ after gel application. Patients will be assessed daily (except at weekends) in oncology and radiotherapy department for evaluation of mucositis, oral pain and lesion measurements. This assessment will be possible due to the chemotherapy and radiotherapy treatment schedule. Patients will record in a diary how the gel was administered, schedules, concomitant use with other medications and reports of adverse effects.

\begin{tabular}{|c|c|c|c|}
\hline $\begin{array}{l}\text { Components of } \\
\text { formulation }\end{array}$ & Function & $\begin{array}{l}\text { Weight } \\
\text { (g) }\end{array}$ & $\%$ \\
\hline A. chica extract & Active pharmacological & 2.5 & 2.5 \\
\hline Hydroxyethyl cellulose & Base & 95.0 & 95.0 \\
\hline Propylene glycol & Emollient & 2.5 & 2.5 \\
\hline
\end{tabular}




$\begin{aligned} & \text { Table } 2 \\
& \text { scale of the effects of radiotherapy on oral mucositis }\end{aligned}$
\begin{tabular}{ll} 
Grade & Sign/symptom \\
\hline 0 & No reaction \\
1 & $\begin{array}{l}\text { Mild erythema, dry desquamation, epilation, } \\
\text { decreased sweating }\end{array}$ \\
2 & $\begin{array}{l}\text { Moderate erythema, glossy exudative plaque } \\
\text { dermatitis and moderate oedema }\end{array}$ \\
3 & $\begin{array}{l}\text { Exudative dermatitis in addition to skin folds, } \\
\text { severe oedema }\end{array}$ \\
4 & Ulceration, haemorrhage, necrosis \\
\hline
\end{tabular}

The low-intensity $850 \mathrm{~nm}$ laser is applied in the affected area at least one section of $10 \mathrm{~s}$. Patients are evaluated daily (except on weekends) to assess the degree of mucositis, pain and measures of oral lesions. Additional sections will be applied if additional lesions are identified in other areas of the oral cavity. The procedure will be performed in the Department of Laser Medicine or Stomatology of HC-Unicamp.

To ensure a coherent comparison, both treatments will be applied for up to 2 weeks and to avoid measurement bias, other topic treatments will not be allowed to the patients, only the assigned treatment.

\section{Outcomes}

Primary outcome is mean duration of mucositis in days, measured by the mean and SD of each group, and association will be assessed by mean difference and $95 \%$ CI.

Mucositis will be measured by the Radiation Therapy Oncology Group scale to classify the effects of radiotherapy (table 2).

Secondary outcome will include pain assessment, using a Visual Analogue Scale (VAS) from 0 (no pain) to 10 (unbearable pain) and quality adjusted life years (QALY) by European Quality of Life 5-Dimensions (EQ-5D). ${ }^{17}$ Furthermore, a measurement of the diameter, in millimetres, of the oral lesion using a millimetre periodontal probe (Williams's model) will be taken. Each patient will have their mouth photographed at enrolment and during intervention for documentation of the degree and extension of oral mucositis. Photographs will be read in ImageJ software. ${ }^{18}$

\section{Participant timeline}

The recruitment started in November 2017. Each participant will be enrolled in the study for approximately 4 months: patients who develop oral mucositis from grade 2 or worse will be assessed for eligibility. At this point, those who accept to participate will sign the free and informed consent term (-t1). Baseline characteristics of participants at this moment includes grade of oral mucositis and quality of life assessments. Patients will be allocated to one of the study groups by means of randomisation ( $\mathrm{t} 0$ ); the first patient was enrolled on 22 November 2017. On initiation of study interventions, patients will be treated either with $A$. chica or laser until wound healing (t1). In the first day of intervention, patients allocated to A. chica will be monitored during application of herbal gel to assure procedure comprehensiveness. Monitoring is performed in a daily basis with assessment of mucositis grade by trained professionals and diameter measurement by photographs and millimetre periodontal probe (t2). Treatments will be concluded once mucositis is healed. A blinded accessor will evaluate mucositis cure after referred by the study team (t3). At this point, the gel tube will be weighed to indirectly assess patient's compliance. At close-out, data will be analysed by a blinded researcher following the procedures described in the statistical analyses (t4). The schedule of enrolment, interventions and assessments is described in table 3 .

\section{Sample size}

Sample size was determined considering a CI of $5 \%$ (alpha 0.05 ), study power of $80 \%$ (beta of 0.20 ) and SD of mean duration of mucositis of 3.40 days and an expected difference in means between groups of 1.70 , according to a systematic review of low-level laser therapy in oral mucositis. ${ }^{19}$ This led to 63 individuals in each group, to which we added $10 \%$ to compensate eventual losses leading to 70 patients to be included per group.

\section{Recruitment}

Recruiters will be present at the oncology department during appointments at the head and neck cancer at HC-Unicamp clinic to identify eligible patients. Approximately five new head and neck cancer cases are attended at oncology department per month. We expect to conclude recruiting in 2 years.

\section{Sequence generation}

Block randomisation of four patients will be performed to ensure balance of groups throughout recruitment ( 35 blocks of 4 patients each). The generation of the randomisation sequence will be performed at www.randomization.com.

The list will be in the possession of a researcher who is not related to the patient recruitment process. After determining the eligibility and inclusion of the patient, eligible patients will be allocated by means of opaque envelopes with the group which the next patient will be allocated.

\section{Blinding}

Due to the nature of the interventions, blinding of participants and researchers involved in the assistance will not be possible. The persons responsible for measuring mucositis cure and data analysts will be blinded to the group that each patient belongs to.

\section{Data collection methods}

Baseline assessments will include measurements of QALY, pain, grade of mucositis, measurement of mucositis diameter and photographs of the mouth, laboratory measurements.

Trained personnel will evaluate the duration of mucositis daily by, using the Radiation Therapy Oncology 
Table 3 Schedule of enrolment, interventions and assessments

\begin{tabular}{|c|c|c|c|c|c|c|}
\hline \multirow[b]{3}{*}{ Timepoint } & \multicolumn{6}{|c|}{ Study period } \\
\hline & \multirow{2}{*}{$\begin{array}{c}\text { Enrolment } \\
-t_{1}\end{array}$} & \multirow{2}{*}{$\begin{array}{c}\text { Allocation } \\
t_{0}\end{array}$} & \multicolumn{2}{|l|}{ Post-allocation } & \multirow[b]{2}{*}{$t_{3}$} & \multirow{2}{*}{$\begin{array}{c}\text { Close-out } \\
t_{4}\end{array}$} \\
\hline & & & $t_{1}$ & $t_{2}$ & & \\
\hline \multicolumn{7}{|l|}{ Enrolment } \\
\hline Eligibility screen & $x$ & & & & & \\
\hline Informed consent & $x$ & & & & & \\
\hline Allocation & & $x$ & & & & \\
\hline \multicolumn{7}{|l|}{ Interventions } \\
\hline \multicolumn{7}{|l|}{ Herbal gel } \\
\hline Orientation of herbal gel application & & & $x$ & & & \\
\hline Low-level laser therapy & & & $\gamma$ & & & \\
\hline \multicolumn{7}{|l|}{ Assessments } \\
\hline Quality of life & $x$ & & & & $x$ & \\
\hline Grade of oral mucositis & $x$ & & & $x$ & & \\
\hline Wound diameter & $x$ & & & $x$ & & \\
\hline Sociodemographic characteristics & $x$ & & & & & \\
\hline Adverse event monitoring & & & $x$ & $x$ & $x$ & \\
\hline Statistical analysis & & & & & & $x$ \\
\hline Report writing & & & & & & $x$ \\
\hline
\end{tabular}

Group scale (table 2). These personnel will also evaluate pain using VAS.

Other data include laboratory and clinical assessment of the patients due to the oncological treatment which will be collected on demand.

\section{Data management}

Each patient will have a paper file for registering baseline, daily and outcomes assessment. Data will be recorded into electronic files during the course of the study.

\section{Statistical methods}

The characteristics of the participants will be described in absolute and relative terms and tested by the $\chi^{2}$, Student's t-test, analysis of variance and other relevant tests to assess the similarity between the groups and the balance of randomisation.

The relative risk of the dichotomous results and the mean difference (SD) of the $95 \%$ CI will be calculated for the total study population and relevant subgroups. Intention-to-treat analysis will be adopted.

If pertinent, the regressions will be calculated to identify factors associated with the results found to elucidate relevant prognostic factors.

The researcher responsible for the analysis of the data will be blind to the groups to which the patients belong, to guarantee the isonomy of the analyses.

\section{Data monitoring}

Primary and secondary outcomes will be assessed in interim analysis to evaluate the need to terminate the trial.

\section{Harms}

The observed adverse events will be recorded in a diary by patients and assessed by a physician as needed. Clinical tolerance (signs and symptoms, adverse events, laboratory parameters), vital signs (blood pressure, pulse and temperature) and ECG will be analysed according to medical, pharmaceutical and dental criteria.

\section{Auditing}

An experienced researcher in quality control will audit the study every 6 months. Corrective measures will be deployed and properly recorded.

\section{Protocol amendments}

If there is a need for any changes to this protocol, the research ethics committee will be communicated for amendment approval.

\section{Consent}

The recruiters will obtain informed consent from each patient to be included (online supplementary appendix). Such researchers will explain the research objective and invite eligible patients. All procedures will be performed after obtaining the informed consent form signed by patients who agree to participate in the proposed study. Confidentiality will be assured to all patients.

\section{Confidentiality}

Each participant will be encoded by a number to guarantee information confidentiality. Any files containing identifiable data will be stored in locked file cabinets, 
and only researchers will have access to participants' information.

\section{Access to data}

After completion and analysis of data, data will be fully accessible to all study researchers. External access for data will be available on request.

\section{Ancillary and post-trial care}

If the participants develop the treatment needs after the test is completed, they will be sent to HC-Unicamp, São Paulo, at the discretion of the medical researchers involved in this study.

\section{Dissemination policy}

Results will be publicised in journal papers reporting primary and secondary outcomes. Data will be published as grouped data. No participants' individual information will be available as assured in the informed consent form of each participant.

Partial and final reports will be sent to the funding agency.

\section{Patient and public involvement}

The research question and outcome measures took into consideration indirect assessment of patients' priorities, experience and preferences by the personnel from oncology and radiotherapy departments. Patients were not involved in the design of this study nor in the assessment of burden of the intervention. Each patient will be involved in their own recruitment to and personal assessments of oral mucositis' progress. At the end of the study, each patient will receive a brochure summarising in plain language the results of the study along with a letter of gratitude for their participation in the study. Their contributorship will also be thanked in the acknowledgements of the final publication.

Acknowledgements The authors would like to thank the Fundação de Amparo à Pesquisa do Estado de São Paulo - FAPESP (grant 2015/08338-6) for funding this trial.

Contributors All authors contributed for the design of the work; NdCAQ, MPJ, TFG and MAF drafted the paper. IMdOS, CSPL, MCdMM, ACDR, EBP, VHKG, JEdC and MAF revised it critically for important intellectual content. All authors approved the final version to be published and agree to be accountable for all aspects of the work in ensuring that questions related to the accuracy or integrity of any part of the work are appropriately investigated and resolved.

Funding Sao Paulo State Foundation for Research Support (Fundação de Amparo à Pesquisa do Estado de São Paulo, FAPESP), process: 2015/08338-6 and Faculty of Pharmaceutical Sciences, University of Campinas.

Competing interests MAF detains patents related to Arrabiadaea chica (patents: PI01811005081, PI018120047755). The others authors declare no conflicts of interests.

Patient consent Not required.

Ethics approval This clinical trial was approved by the ethics committee of research in humans at the Faculty of Medical Sciences of Unicamp (report no.
$1,613,563$ of 29 June 2016; certificate of presentation for ethical appreciation at Brazil Platform [(CAAE]): 55933516.3.0000.5404).

Provenance and peer review Not commissioned; externally peer reviewed.

Open access This is an open access article distributed in accordance with the Creative Commons Attribution Non Commercial (CC BY-NC 4.0) license, which permits others to distribute, remix, adapt, build upon this work non-commercially, and license their derivative works on different terms, provided the original work is properly cited, appropriate credit is given, any changes made indicated, and the use is non-commercial. See: http://creativecommons.org/licenses/by-nc/4.0/.

\section{REFERENCES}

1. Treister N, Sonis S. Mucositis: biology and management. Curr Opin Otolaryngol Head Neck Surg 2007;15:123-9.

2. Mallick S, Benson R, Rath GK. Radiation induced oral mucositis: a review of current literature on prevention and management. Eur Arch Otorhinolaryngol 2016;273:2285-93.

3. De Sanctis V, Bossi P, Sanguineti G, et al. Mucositis in head and neck cancer patients treated with radiotherapy and systemic therapies: Literature review and consensus statements. Crit Rev Oncol Hematol 2016;100:147-66.

4. Bossi P, Numico G, De Santis V, et al. Prevention and treatment of oral mucositis in patients with head and neck cancer treated with (chemo) radiation: report of an Italian survey. Support Care Cancer 2014;22:1889-96.

5. Mosel DD, Bauer RL, Lynch DP, et al. Oral complications in the treatment of cancer patients. Oral Dis 2011;17:550-9.

6. Cheng KK. Oral mucositis, dysfunction, and distress in patients undergoing cancer therapy. J Clin Nurs 2007;16:2114-21.

7. Elad S, Luboshitz-Shon N, Cohen T, et al. A randomized controlled trial of visible-light therapy for the prevention of oral mucositis. Oral Oncol 2011;47:125-30.

8. Bayer S, Kazancioglu HO, Acar AH, et al. Comparison of laser and ozone treatments on oral mucositis in an experimental model. Lasers Med Sci 2017;32:673-7.

9. Franco P, Martini S, Di Muzio J, et al. Prospective assessment of oral mucositis and its impact on quality of life and patient-reported outcomes during radiotherapy for head and neck cancer. Med Oncol 2017:34:81.

10. Brasil. Ministério da Saúde, 2009. Relação Nacional de Plantas Medicinais de Interesse ao SUS - RENISUS Brasilia: Ministério da Saúde http://portalsaude.saude.gov.br/images/pdf/2014/maio/07/ renisus.pdf.

11. Jorge MP, Madjarof C, Gois Ruiz AL, et al. Evaluation of wound healing properties of Arrabidaea chica Verlot extract. $J$ Ethnopharmacol 2008;118:361-6.

12. Jorge MP. Atividade cicatrizante de microencapsulados de extrato bruto etanólico de Arrabidaea chica (Humb. \& Bonpl.) Verlot. São Paulo;, Brazil: Universidade Estadual de Campinas, 2013.

13. Aro AA, Simões GF, Esquisatto MA, et al. Arrabidaea chica extract improves gait recovery and changes collagen content during healing of the Achilles tendon. Injury 2013;44:884-92.

14. de Oliveira Sousa IM. Avaliação da estabilidade do extrato seco e formulações de bases semi sólidas, contendo Arrabidaea chica Verlot, para uso em cicatrização. São Paulo", Brazil: Universidade Estadual de Campinas, 2013.

15. dos Santos VC, Longo TB, Garcia AL, et al. Evaluation of the mutagenicity and genotoxicity of Arrabidaea chica Verlot (Bignoneaceae), an Amazon plant with medicinal properties. J Toxicol Environ Health A 2013;76:381-90.

16. Servat-Medina L. Arrabidaea chica Verlot: Formulações de liberação sustentada para aplicação em úlceras de mucosa e pele. São Paulo;, Brazil: Universidade Estadual de Campinas, 2014.

17. Szende A, Oppe M, Devlin N. EQ-5D Value sets: inventory, comparative review and user guide. Berlin, Germany: Springer, 2007.

18. Schneider CA, Rasband WS, Eliceiri KW. NIH Image to ImageJ: 25 years of image analysis. Nat Methods 2012;9:671-5.

19. Bjordal JM, Bensadoun RJ, Tunèr J, et al. A systematic review with meta-analysis of the effect of low-level laser therapy (LLLT) in cancer therapy-induced oral mucositis. Support Care Cancer 2011;19:1069-77. 